\title{
Crystalline Microstructure of Corundum Fillers Determined from Powder X-Ray Diffraction Patterns
}

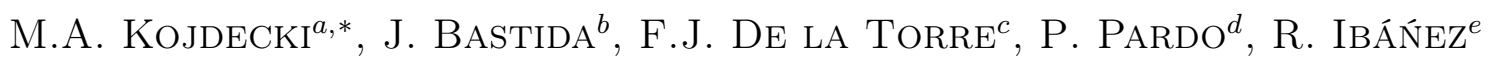 \\ AND M.M. URQUIOLA ${ }^{f}$ \\ ${ }^{a}$ Institute of Mathematics and Cryptology, Military University of Technology, 00-908 Warsaw, Poland \\ ${ }^{b}$ Department of Geology, University of Valencia, 46100 Burjasot, Valencia, Spain \\ ${ }^{c}$ Department of Chemical Engineering, University of Valencia, 46100 Burjasot, Spain \\ ${ }^{d}$ Department of Inorganic Chemistry, University of Valencia, 46100 Burjasot, Spain \\ ${ }^{e}$ Institute of Materials Science, University of Valencia, 46980 Paterna, Valencia, Spain \\ ${ }^{f}$ Ceinmat S.L, Scientific Park of the University of Valencia, 46980 Paterna, Spain
}

\begin{abstract}
X-ray-diffraction microstructural analysis was performed for corundum powders produced from Bayer aluminium hydroxides in different ways and for high purity corundum powders produced from other raw materials. Crystalline microstructure characterised by prevalent crystallite shape, volume-weighted crystallite size distribution and second-order crystalline lattice strain distribution was determined through modelling crystallite shapes as hexagonal prisms, with the resulting mean volume-weighted standardised crystallite size in the range 406-1941 $\AA$, height-to-base-diagonal ratio in the range $0.68-0.94$ and the mean-absolute second-order strain in the range 0.028$0.087 \%$. Crystallite size distributions were found to be well approximated as bimodal logarithmic-normal ones and consequently four types of microstructure were recognized as depending on precursors and methods of production.
\end{abstract}

DOI: 10.12693/APhysPolA.130.1000

PACS/topics: 81.05.Je, 61.72.Dd

\section{Introduction}

Alumina is one of the most important ceramics for structural applications, preferentially in the chemically most stable form of corundum $\left(\alpha-\mathrm{Al}_{2} \mathrm{O}_{3}\right)$. The decrease of crystalline grain sizes improves the hardness and wear resistance of dense sintered products; fine powders of corundum are chemically much more resistant than transitional alumina phases [1]. Alumina powders have wide range of applications [2] also as miscellaneous mineral fillers in plastics (mainly in polyesters and epoxies) that improve electrical resistivity, thermal conductivity, chemical inertness, hardness, abrasion resistance [3], form hard protective surfaces and reduce coefficient of thermal expansion. Raw powders of $\alpha-\mathrm{Al}_{2} \mathrm{O}_{3}$ for non-metallurgical use are obtained traditionally by thermal treatment of aluminium hydroxides which decompose from bauxite via Bayer processes. During calcination a series of transition aluminas, $\gamma-, \delta$-, and $\theta$-phases develop, and ultimately $\alpha-\mathrm{Al}_{2} \mathrm{O}_{3}$ is produced through $\theta-\mathrm{Al}_{2} \mathrm{O}_{3}$ phase transformation and subsequent micronisation of the obtained powder, as reported in many papers [4]. The main categories [5] of commercial alumina according to the method of production are: calcined, fused and tabular aluminas, featuring the contents of alpha-alumina above $75 \%$, crystalline grain sizes in the range $50-500 \mu \mathrm{m}$ and different levels of chemical impurities (especially $\mathrm{Na}_{2} \mathrm{O}$ in the range of $0.2-0.6 \%$ being relevant). Transition aluminas are known generally as gamma-aluminas or activated

\footnotetext{
*corresponding author; e-mail: m.kojdecki@poczta.onet.pl
}

aluminas [5]. The main markets of aluminas were described in Roskill report of 2008 [6]. Ultra-high-purity $\alpha-\mathrm{Al}_{2} \mathrm{O}_{3}$ with large specific surface is produced by calcining different aluminium salts or from aluminium alkoxides [7].

The characterisation of alpha-alumina powders with using X-ray diffraction (XRD) usually includes identification of contaminant phases and mean apparent crystallite size. Morphological or textural descriptions are eventually obtained via electron microscopy techniques. Some papers present more complete characterisation based on XRD patterns including mean crystallite size and strain (e.g. [8-11]), crystallite size distribution [12], and rarely crystallite size and shape distributions [13]. Densification and re-crystallisation can be achieved by overgrinding of nanocrystalline corundum [14] but usually the maximum of frequency of crystallite size distributions migrates to smaller crystallite sizes after milling (e.g. [15]). The method of microstructural analysis of powder XRD patterns applied in [16] has been used in the present work for microstructural evaluation of industrial alpha-alumina fillers. This method exploits a model of polycrystalline material combined with a description of XRD line profiles including contributions from crystallite shapes and sizes and from strains, enabling the determination of the crystallite size distribution and strain distribution together with the estimation of prevalent crystallite shape.

\section{Materials and data collection}

The studied materials (nine specimens), reported in Table I (and further) as A2, A3, A5, A6, A10 and A11, 
TABLE I

Macroscopic characteristics of corundum samples: $B D-$ bulk density $\left[\mathrm{g} / \mathrm{cm}^{3}\right], L *$ - whiteness, $d_{0.5}-$ median of volume-equivalent spherical particle distribution $[\mu \mathrm{m}]$.

\begin{tabular}{c|c|c|c|c|c|c|c|c}
\hline \hline & A2 & A3 & A5 & A6 & A10 & A11 & A40 & AL10 \\
\hline$B D$ & 1.33 & 1.11 & 1.37 & 1.18 & 1.23 & 1.33 & 0.82 & 1.05 \\
$L *$ & 91.1 & 89.2 & 92.3 & 82.4 & 91.5 & 88.8 & 91.5 & 90.1 \\
$d_{0.5}$ & 10 & 6.2 & 12 & 17 & 6.5 & 9 & 9 & 12.6
\end{tabular}

were respectively calcined, super ground, hard calcined, super ground thermally reactive, ground calcined and white fused ultra ground aluminas produced from aluminium hydroxides through Bayer process; A40, AL10 and AL11 were high purity aluminas produced (calcined) from raw materials different to Bayer aluminium hydroxides (potassium alum in case of AL10 and AL11). Relevant properties of the investigated fillers were estimated: the Brunauer-Emmett-Teller (BET) specific surface area [17] — Table II, whiteness value under CIE 1931 standard (by a CR400 Minolta colorimeter with using CR400 Minolta software), bulk density [18] and distribution of particle size (a volume-equivalent sphere diameter) in wet dispersion (by Mastersizer 2000, Malvern
Instruments) - Table I. Morphological features (shape, size, aggregation) were observed by field emission scanning electron microscopy (FESEM) in a HITACHI S4800 microscope using a field emission gun with a resolution of $1.4 \mathrm{~nm}$ at $1 \mathrm{kV}$. Chemical analysis for major elements were performed (4E-XRF routine, Actlabs Laboratories, Ancaster, Canada).

Powder XRD patterns of the fillers were obtained in a Bruker D8 Advance diffractometer (equipped with a LynxEye detector, working at $40 \mathrm{kV}$ and $30 \mathrm{~mA}$, with $\mathrm{Cu} K_{\alpha}$ radiation and graphite monochromator). Eva program of Diffrac Plus System working with PDF2 of ICDD data base was used for phase identification. Data were collected by step scanning (with step size of $0.02^{\circ}$ and step time of $96 \mathrm{~s}$ ).

\section{Results of powder X-ray diffraction microstructural analysis and observations}

Small $\mathrm{Na}_{2} \mathrm{O}$ contents below $0.1 \%$ was observed only in samples A3, A6, and A10. Sodium aluminium oxide as contaminant was not present only in samples A10 and AL10. FESEM images in Fig. 1 show the morphological features of the samples.
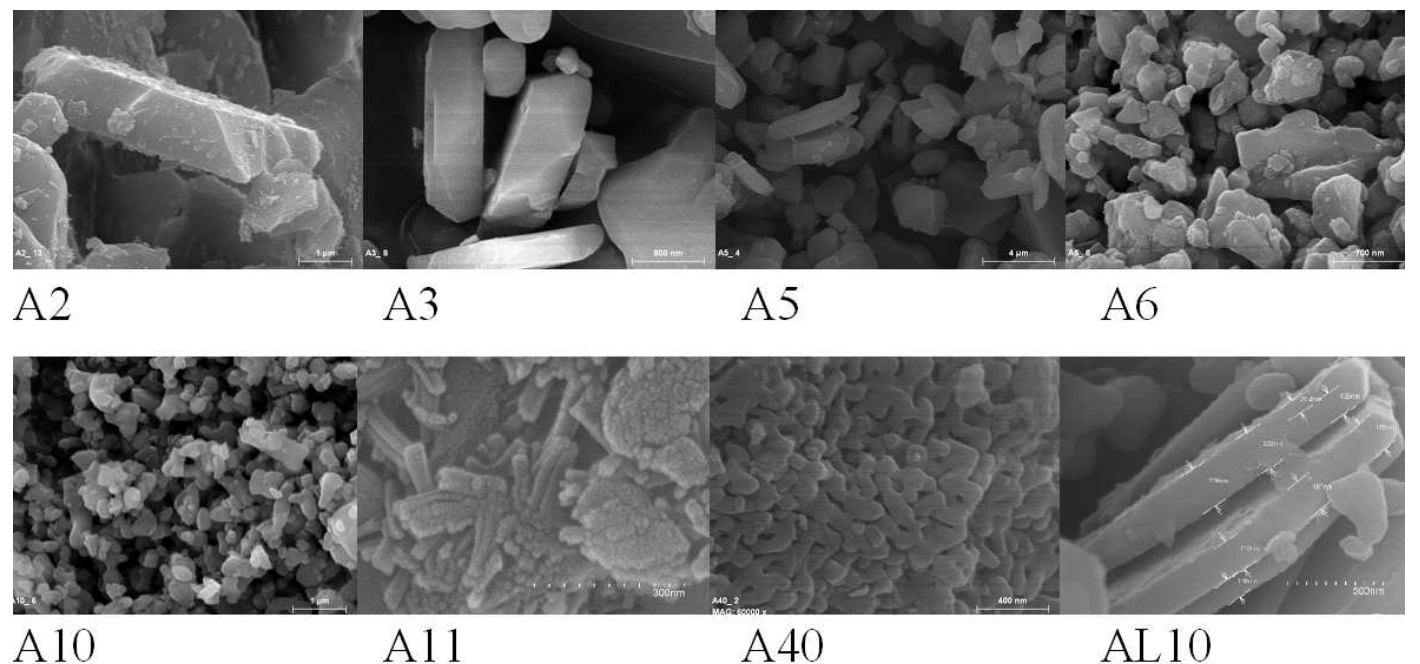

Fig. 1. FESEM images of eight samples.

Crystals of natural corundum are usually roughly barrel shaped, and rarely thick tabular along $\langle 00.1\rangle$ which is a frequent form in these industrial corundum samples. Thus platelets of pinacoidal form $\langle 00.1\rangle$ can be clearly distinguished in samples A2, A3, A5 and A11, with the longer edges of around $10 \mu \mathrm{m}$, and thickness above $1 \mu \mathrm{m}$ (observed in A2), and with edges up to $2 \mu \mathrm{m}$ and thickness below $0.3 \mu \mathrm{m}$ in AL10. Spherular aggregates of crystallites were found in samples A40 and AL10, having smaller values of bulk density. Except for A40 and AL10, all studied fillers comprise predominantly blocky particles. In addition platelets or laths of partition with greater long faces of around $10 \mu \mathrm{m}$ can be recognized in A2 sample. An example of typical lamellar crystal made by a combination of two forms: a prevailing pinacoid and a bipyramid is shown in Fig. 2 (drawn by Shape program [19]).
Figure 3 includes the obtained XRD patterns, and shows minor phases (sodium aluminates) identified in addition to corundum. The crystalline microstructure of corundum specimens, characterised by a prevalent crystallite shape, a volume-weighted crystallite size distribution and a second-order crystalline lattice strain distribution was determined by method described previously [16]. The crystallite shapes were well modelled as hexagonal prisms, which might be similar to possible forms as in Fig. 2 but with plane lateral $\langle 11.0\rangle$ or $\langle 10.0\rangle$ or $\langle 01.0\rangle$ prism faces between pinacoid $\langle 00.1\rangle$ faces; results are shown in Table II including samples of Table I with an additional one (AL11) obtained as AL10 [20] but through quenching at $1100^{\circ} \mathrm{C}$ instead of $1000^{\circ} \mathrm{C}$, and with gentle disaggregating in both cases. The characteristics of crystalline microstructure were determined from sets of non-overlapping line profiles for reflections 01.2 , 
TABLE II

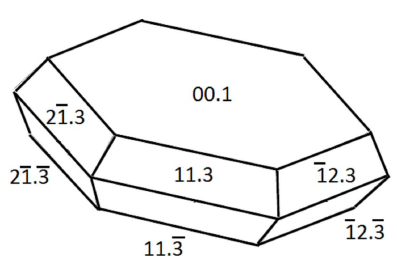

Fig. 2. Typical morphology frequently recognized in platelet-shaped grains.

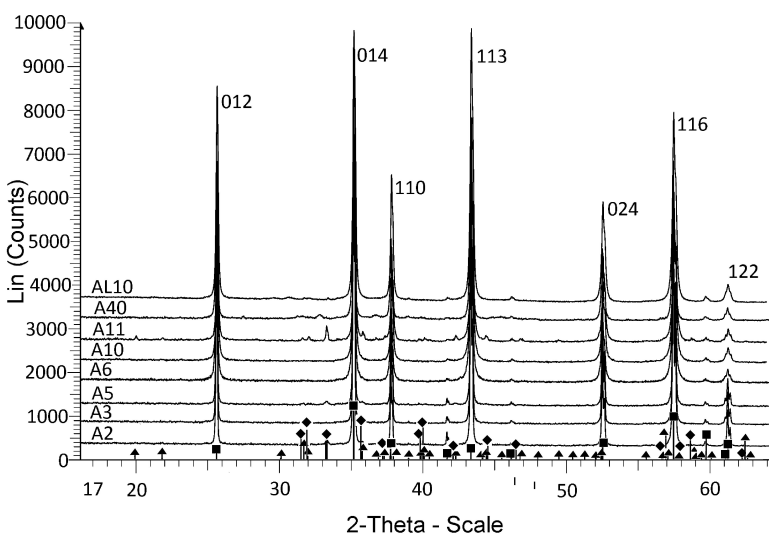

Fig. 3. X-ray diffraction patterns. Line labels ICDD patterns, squares - No. 046-1212 (corundum $)$, diamonds - No. 021-1095, $\left(\mathrm{NaAl}_{7} \mathrm{O}_{11}=\right.$ 0.5 $\left(\mathrm{Na}_{2} \mathrm{O} \cdot 7 \mathrm{Al}_{2} \mathrm{O}_{3}\right)$, triangles - No. 00-021-1096 $\left(\mathrm{NaAl}_{11} \mathrm{O}_{17}=0.5\left(\mathrm{Na}_{2} \mathrm{O} \cdot 11 \mathrm{Al}_{2} \mathrm{O}_{3}\right)\right.$.

$01.4,11.0,11.3,02.4,11.6,12.4,03.0(\mathrm{~A} 2, \mathrm{~A} 3, \mathrm{~A} 5, \mathrm{~A} 6$, $\mathrm{A} 40$ ) and $01.2,01.4,11.0,11.3,02.4,11.6$ (A10, A11, AL10, AL11) that could be separated and extracted from XRD patterns. To compare results for different samples with different prevalent crystallite shapes a standardised size equal to cube root of volume is used (as mean volume-weighted sizes $\mathrm{T}, \mathrm{T} 1$ and $\mathrm{T} 2$ in Table II). The standardised crystallite size distributions (Fig. 4) calculated from XRD patterns were found to be bimodal logarithmic-normal ones in good approximation. In samples A10, AL10 and AL11 the contribution of fraction of smaller crystallites is larger than in other samples. In Table II the averaged characteristics of all samples are collected. Based on the magnitudes of specific surface area (SA) computed with accounting contribution of selected crystallite faces and measured by nitrogen adsorption (BET - BS) two simple models of crystalline grains for each sample have been postulated. The grains were modelled as comprising hexagonal-prismatic bricks of the same crystallites aligned in layers with plane bases of hexagons organised in rings around one central hexagon; the numbers of rings and layers were chosen to achieve $\mathrm{BS}=\mathrm{SA}$ in two cases - for tabular or blocky shape. The estimated mean grain sizes agree with estimates of sizes of particles from images in Fig. 1. The logarithmic-normal components of the crystallite size distributions are considered to be related with different processes involved in
Averaged microstructure characteristics of corundum fillers: D - greater diagonal of mean hexagonal crystallite base $[\AA]$, $\mathrm{C}$ - height of mean hexagonal prism along [001] [^], T, $\mathrm{T} 1, \mathrm{~T} 2$ - standardised mean crystallite sizes for whole sample and fractions $[\AA], \mathrm{E}$ - mean-absolute second-order crystalline lattice strain $\left[\times 10^{-4}\right], \mathrm{S}, \mathrm{S} 1, \mathrm{~S} 2$, and $\mathrm{Z}-$ standard deviation for distributions relating $\mathrm{T}, \mathrm{T} 1, \mathrm{~T} 2$ and $\mathrm{E}$ respectively, N1, N2 - relative volumes of fractions, $\mathrm{RH}$ - relative error of approximating experimental line profiles measured by line profiles simulated for a model polycrystal with calculated microstructure characteristics, SA - specific surface area calculated for population of crystallites $\left[\mathrm{m}^{2} / \mathrm{g}\right], \mathrm{BS}-$ BET specific surface area $\left[\mathrm{m}^{2} / \mathrm{g}\right], \mathrm{DH}-$ model grain base diameter $[\mu \mathrm{m}]$ over model grain height $[\mu \mathrm{m}]$, and $\mathrm{NC}$ - number of crystallites per model grain.

\begin{tabular}{|c|c|c|c|c|c|c|c|c|c|}
\hline Sample & A2 & A3 & A5 & A6 & A10 & A11 & A 40 & AL10 & AL11 \\
\hline $\mathrm{D}$ & 2347 & 1663 & 1587 & 1559 & 1100 & 1667 & 1169 & 478 & 912 \\
\hline $\mathrm{C}$ & 2044 & 1246 & 1409 & 1193 & 880 & 1398 & 796 & 450 & 622 \\
\hline $\mathrm{C} / \mathrm{D}$ & 0.87 & 0.75 & 0.89 & 0.77 & 0.80 & 0.84 & 0.68 & 0.94 & 0.68 \\
\hline $\mathrm{T}$ & 1941 & 1308 & 1321 & 1235 & 884 & 1361 & 891 & 406 & 695 \\
\hline $\mathrm{S} / \mathrm{T}$ & 0.50 & 0.54 & 0.54 & 0.59 & 0.91 & 0.71 & 0.46 & 0.66 & 0.66 \\
\hline $\mathrm{T} 1$ & 1386 & 837 & 911 & 669 & 412 & 455 & 668 & 285 & 386 \\
\hline $\mathrm{S} 1 / \mathrm{T} 1$ & 0.87 & 0.64 & 0.75 & 0.94 & 0.93 & 0.70 & 0.87 & 0.90 & 0.82 \\
\hline N1 & 0.27 & 0.35 & 0.33 & 0.36 & 0.67 & 0.36 & 0.24 & 0.44 & 0.45 \\
\hline $\mathrm{T} 2$ & 2310 & 1663 & 1654 & 1630 & 1793 & 2017 & 1022 & 558 & 1043 \\
\hline $\mathrm{S} 2 / \mathrm{T} 2$ & 0.45 & 0.49 & 0.50 & 0.44 & 0.37 & 0.52 & 0.42 & 0.59 & 0.50 \\
\hline $\mathrm{N} 2$ & 0.73 & 0.65 & 0.67 & 0.64 & 0.33 & 0.64 & 0.76 & 0.56 & 0.55 \\
\hline $\mathrm{T} 1 / \mathrm{T} 2$ & 0.60 & 0.50 & 0.55 & 0.41 & 0.23 & 0.23 & 0.65 & 0.51 & 0.37 \\
\hline $\mathrm{E}$ & 4.5 & 2.8 & 3.0 & 8.7 & 5.8 & 6.8 & 6.3 & 8.7 & 7.8 \\
\hline $\mathrm{Z} / \mathrm{E}$ & 1.62 & 1.83 & 1.68 & 1.42 & 1.41 & 1.44 & 1.44 & 1.25 & 1.34 \\
\hline RH & 0.081 & 0.142 & 0.141 & 0.068 & 0.063 & 0.057 & 0.062 & 0.167 & 0.080 \\
\hline SA & 11.0 & 15.8 & 16.2 & 21.3 & 42.1 & 22.3 & 23.1 & 63.1 & 38.7 \\
\hline BS & 1.48 & 1.49 & 2.23 & 2.58 & 1.45 & 1.21 & 1.46 & 4.89 & \\
\hline $1 \mathrm{DH}$ & $\begin{array}{l}3.5 \\
0.8\end{array}$ & $\begin{array}{l}2.5 \\
1.0\end{array}$ & $\frac{1.5}{0.9}$ & $\begin{array}{l}\frac{1.5}{1.0} \\
\end{array}$ & $\begin{array}{l}5.6 \\
1.6\end{array}$ & $\begin{array}{l}6.2 \\
1.4\end{array}$ & $\begin{array}{l}2.7 \\
1.0\end{array}$ & $\begin{array}{l}1.5 \\
0.3\end{array}$ & \\
\hline $1 \mathrm{NC}$ & 868 & 1736 & 546 & 728 & 46998 & 13870 & 6564 & 5514 & \\
\hline $2 \mathrm{DH}$ & $\frac{1.8}{2.0}$ & $\frac{1.6}{2.6}$ & $\frac{1.2}{1.3}$ & $\frac{1.2}{1.3}$ & $\begin{array}{l}3.3 \\
3.5\end{array}$ & $\frac{3.0}{3.5}$ & $\frac{1.7}{2.0}$ & $\frac{0.6}{0.8}$ & \\
\hline $2 \mathrm{NC}$ & 610 & 1911 & 549 & 671 & 36760 & 8275 & 5425 & 2873 & \\
\hline
\end{tabular}

the production of the investigated powders. In the case of non-grounded samples AL10 and AL11 they must be only referred to nucleation and growth.

\section{Conclusions}

Different values of specific surface area calculated for crystallites and measured by nitrogen adsorption was observed. The relationship between sizes and shapes of aggregates (crystalline grains) observed by FESEM and sizes and shapes of crystallites estimated from XRD pattern was found to explain this difference. On average a grain comprises hundreds or thousands of crystallites and features rather small second-order crystalline lattice strain (with mean-absolute strain smaller than 0.001).

Several types of XRD microstructures were recognized according to volume contributions of the fractions of smaller and larger crystallites and ratios of corresponding standardised mean crystallite sizes computed from logarithmic-normal components of the bimodal volumeweighted crystallite size distributions (shown in Fig. 4): (t1) $\mathrm{N} 1 \approx 0.33$ and $\mathrm{T} 1 / \mathrm{T} 2 \approx 0.5-\mathrm{A} 3, \mathrm{~A} 5, \mathrm{~A} 6$; (t2) $\mathrm{N} 1 \approx 0.25$ and $\mathrm{T} 1 / \mathrm{T} 2 \approx 0.6-\mathrm{A} 2, \mathrm{~A} 40 ;(\mathrm{t} 3)$ $\mathrm{T} 1 / \mathrm{T} 2 \approx 0.23-\mathrm{A} 10$ with $\mathrm{N} 1 \approx 0.67$ and $\mathrm{A} 11$ with 
$\mathrm{N} 1 \approx 0.33 ;(\mathrm{t} 4) \mathrm{N} 1 \approx 0.45-\mathrm{AL} 10$ with $\mathrm{T} 1 / \mathrm{T} 2 \approx 0.51$ and AL11 with $\mathrm{T} 1 / \mathrm{T} 2 \approx 0.37$. These characteristics evidently reflect methods of production — raw materials and processes of calcination (including nucleation and growth of crystallites) or grinding. Particularly, in samples A10 and A11 (t3) the fractions of smaller crystallites are similar to each other as well as the fractions of larger crystallites (with similar shapes and mean crystallite sizes around 10\% larger in A11 than in A10) but contribute differently; in samples AL10 and AL11 (t4) the increase of processing temperature results in increase of mainly sizes of larger (second fraction) crystallites with preserving volume contents of both fractions, but change of prevalent crystallite shape (from $\mathrm{C} / \mathrm{D} \approx 0.94$ to $\mathrm{C} / \mathrm{D} \approx 0.68$ ). These conclusions are basic for further study of mutual influence of crystalline microstructure resulting from production processes and macroscopic properties of corundum powders.

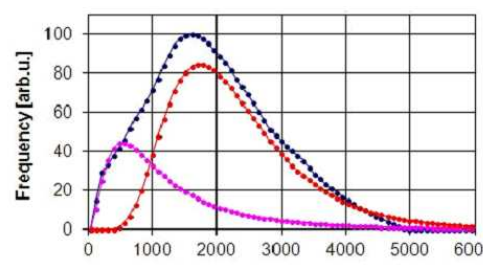

A2

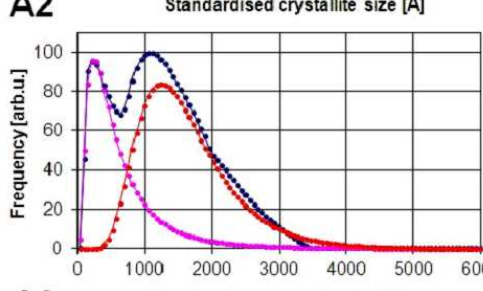

A6

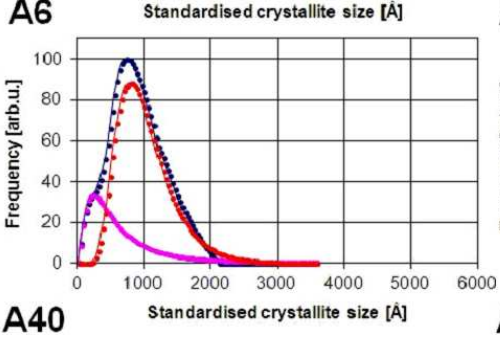

A40

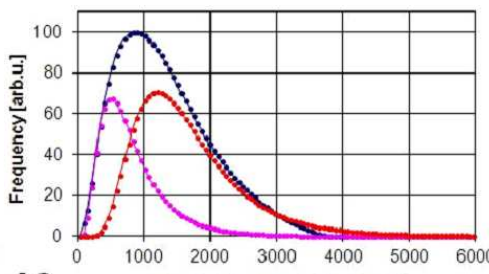

A3

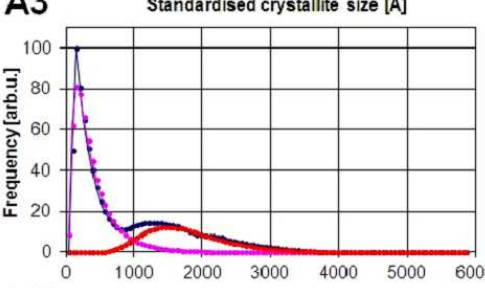

A10

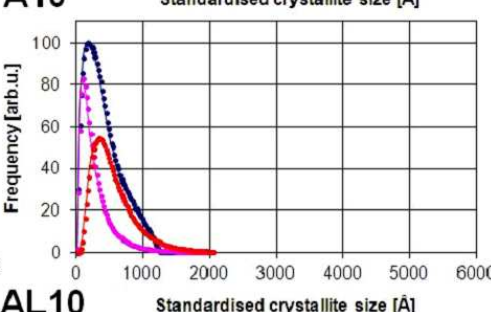

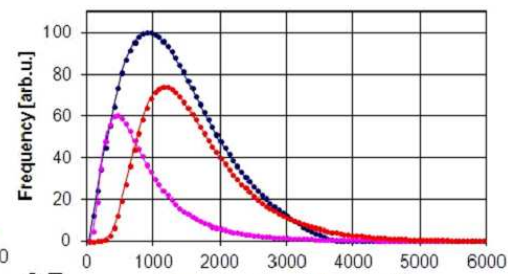

A5

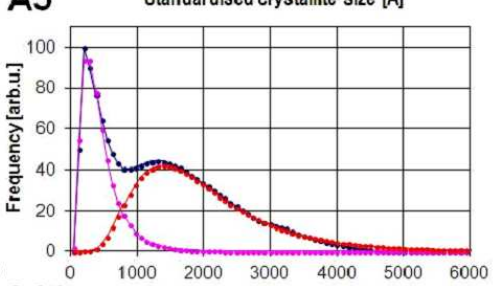

A11

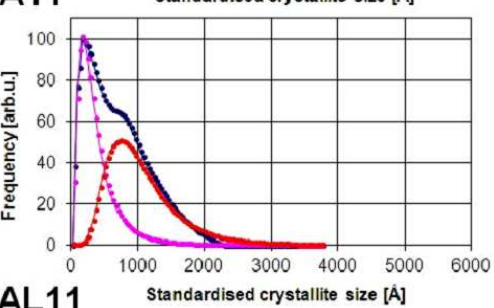

Fig. 4. Crystallite size distributions computed from XRD patterns and both components of each approximation by a bimodal logarithmic-normal distribution.

\section{Acknowledgments}

This paper was supported by Universitat de València, Programa Valoritza i Transfereix VLC Campus.

\section{References}

[1] A. Krell, H. Ma, NanoStruct. Mater. 11, 1141 (1999).

[2] L.H. Baumgartner, in: Alumina Chemicals: Science and Technology Handbook, Ed. D.H. LeRoy, The American Ceramic Society, Columbus 1990, p. 7.

[3] B.M. Walker, in: Handbook of Fillers for Plastics, Eds. H.S. Katz, J.V. Milewski, Van Nostrand Reinhold, New York 1987, p. 232.

[4] B.K. Gan, I.C. Madsen, J.K. Hockridgea, J. Appl. Crystallogr. 42, 697 (2009).

[5] K.A. Evans, Key Eng. Mater. 122-124, 489 (1996).

[6] Roskill Information Services Ltd, The Economics of Bauxite and Alumina, Roskill Information Reports, London 2008.

[7] G.M. Benítez, L. Pérez Maqueda, P. Pena, J.P. Cosp, Bol. Soc. Esp. Cerám. Vid. 52, 251 (2013).

[8] K. Santra, P. Chatterje, S.P. Gupta, Bull. Mater. Sci. 25, 251 (2002)
[9] M. Bodaghi, A. Mirhabibi, M. Tahriri, Metall. Met. Ceram. 48, 634 (2009).

[10] N. Forouzanmehr, F. Karimadeh, M.H. Enayati, J. Alloys Comp. 478, 257 (2009).

[11] M.V. Grigoriev, S.N. Kulkov, Rus. Phys. J. 53, 1305 (2011).

[12] J. Suchanek, L. Wojciech, J. Am. Ceram. Soc. 93 , 399 (2002).

[13] A.K. Deb, P. Chatterjee, D.P. Gupta, J. Appl. Crystallogr. 40, 33 (2007).

[14] Y.M.S. Meor, P. Wilfred, M. Masliana, Appl. Mech. Mater. 83, 255 (2011).

[15] P. Pardo, J. Bastida, F.J. Serrano, R. Ibańez, M.A. Kojdecki, Clays Clay Miner. 57, 25 (2009).

[16] M.A. Kojdecki, J. Bastida, P. Pardo, P. Amorós, J. Appl. Crystallogr. 38, 888 (2005).

[17] S. Brunauer, P.H. Emmett, E. Teller, J. Am. Chem. Soc. 60, 309 (1938).

[18] NLT-176/74, Norms of Laboratory of Transport and Soil Mechanics, CEDEX, Madrid 1974.

[19] E. Dowty, Am. Miner. 65, 465 (1980).

[20] Patent No. ES 2374479 A1, (2010). 